\title{
Cutaneous mastocytosis treatment: strategies, limitations and perspectives
}

\author{
Justyna Czarny, Magdalena Lange, Hanna Ługowska-Umer, Roman J. Nowicki
}

Department of Dermatology, Venereology and Allergology, Medical University of Gdansk, Gdansk, Poland

Adv Dermatol Allergol 2018; XXXV (6): 541-545

DOI: https://doi.org/10.5114/ada.2018.77605

\begin{abstract}
Mastocytosis is a rare myeloproliferative disease, characterized by excessive proliferation and accumulation of mast cells in the tissues. In cutaneous mastocytosis (CM), mast cells infiltration is limited to the skin, whereas in systemic mastocytosis (SM) internal organs are involved. The first-line treatment in CM is antimediator therapy (mainly $\mathrm{H} 1$ and $\mathrm{H} 2$ antihistamines) and short-term topical corticosteroids. Phototherapy is the second-line therapy which may be considered when antihistamines do not produce the expected improvement. New therapeutic options include omalizumab and KIT-targeting agents. Although the disappearance of skin lesions has been reported as a result of cytoreductive therapies in SM, the use of potentially toxic drugs in CM is not recommended. In all adults with mastocytosis and in pediatric patients with severe CM, a persistently elevated serum tryptase level and anaphylaxis in medical history, equipping with epinephrine autoinjector for use in case of anaphylaxis is recommended.
\end{abstract}

Key words: mastocytosis, treatment, prophylaxis.

\section{Introduction}

Mastocytosis is a rare myeloproliferative disease characterized by excessive proliferation and accumulation of mast cells in various tissues. In cutaneous mastocytosis (CM) mast cells infiltration is limited to the skin, whereas systemic mastocytosis (SM) involves internal organs, particularly bone marrow, lymph nodes, liver and spleen [1-4]. The excessive proliferation of mast cells is mainly caused by genetic aberration, predominately the KIT D816V point mutation which is present in approximately $90 \%$ of adults with SM, compared with $35 \%$ in pediatric mastocytosis [1-5]. In childhood mastocytosis, KIT mutations in other loci (exon 8, 9, 11) are more frequently observed [1-5]. The most common form of mastocytosis in adults is SM, whereas CM predominates in children. Skin signs and symptoms are present in approximately $80 \%$ of all mastocytosis patients [1]. Indolent SM (ISM) is the most common variant of the disease in adults, and it is typically associated with a skin involvement with usually a good prognosis. Mast cell mediator-related symptoms such as itching, flushing, hypotension, abdominal pain, cramping, reflux, ulcers, diarrhea, headache, depression, cognitive symptoms and anaphylaxis occur in both CM and SM. According to the recent European Competence Network on Mastocyto- sis classification, CM is divided into: 1) maculopapular cutaneous mastocytosis (MPCM); 2) diffuse cutaneous mastocytosis (DCM) and 3) mastocytoma of the skin [1]. Diagnosis of CM is based on typical morphology of skin lesions, presence of Darier's sign and an increased number of mast cells in biopsy sections of lesional skin. In unclear cases detection of KIT mutation in skin lesions may confirm the diagnosis of CM [1]. In adults, the diagnosis of CM requires exclusion of systemic involvement $[1,2]$. Patients suffering from CM and ISM have normal or near normal life expectancy compared with the general population. Current treatment options are based mostly on an expert opinion rather than evidence obtained from controlled clinical trials. It is partially due to the fact that mastocytosis is a heterogeneous and rare disease with an estimated prevalence of approximately 1 per 10,000 [4]. Up to now, no therapy has been developed to achieve a total cure of mastocytosis [3-6] (Table 1).

\section{First-line therapy}

The primary goal of CM treatment is the control of mast cell mediator-related symptoms [4, 7]. The antagonists of the histamine receptor are the basis of therapy. Skin symptoms such as pruritus, flushing and the sensa-

Address for correspondence: Justyna Czarny MD, Department of Dermatology, Venereology and Allergology, Medical University of Gdansk, 1 a Kliniczna St, 80-402 Gdansk, Poland, phone: +48 666046 663, e-mail: czarnyjustyna@gmail.com Received: 10.07.2017, accepted: 13.09.2017. 
Table 1. Treatment strategies in CM [4-7]

\begin{tabular}{|c|c|c|c|c|}
\hline \multicolumn{2}{|c|}{$\begin{array}{l}\text { Signs and symptoms } \\
\text { of cutaneous mastocytosis }\end{array}$} & \multirow{2}{*}{$\begin{array}{c}\text { First-line therapy } \\
\text { Short-term therapy with topical } \\
\text { corticosteroids } \\
\text { Treatment is not necessary } \\
\text { in the majority of cases }\end{array}$} & \multirow{2}{*}{$\begin{array}{c}\text { Other therapies } \\
\text { Topical corticosteroids, UVA1, } \\
\text { narrow-band UVB } \\
\text { PUVA } \\
\text { Pimecrolimus }\end{array}$} & \multirow{3}{*}{$\begin{array}{c}\text { Prevention } \\
\text { Identification } \\
\text { and avoidance } \\
\text { triggers factors } \\
\text { including } \\
\text { the patients with } \\
\text { IgE-mediated } \\
\text { allergy }\end{array}$} \\
\hline Skin lesions & MPCM/UP & & & \\
\hline & DCM & $\begin{array}{l}\text { Short-term therapy with topical and } \\
\text { oral corticosteroids }\end{array}$ & $\begin{array}{l}\text { UVA1 } \\
\text { Narrow-band UVB } \\
\text { PUVA }\end{array}$ & \\
\hline & Mastocytoma & $\begin{array}{l}\text { Without treatment or topical } \\
\text { corticosteroids }\end{array}$ & $\begin{array}{c}\text { Surgical excision } \\
\text { Injection with crystalline steroid } \\
\text { solutions } \\
\text { Pimecrolimus }\end{array}$ & \\
\hline \multirow{4}{*}{$\begin{array}{l}\text { Mast cell } \\
\text { mediator- } \\
\text { related } \\
\text { symptoms }\end{array}$} & $\begin{array}{l}\text { Tachycardia } \\
\text { Hypotension } \\
\text { Headache }\end{array}$ & $\begin{array}{l}\text { Second-generation } \mathrm{H} 1 \text { antihistamines } \\
\text { If symptoms persist, increase the dose } \\
\text { up to } 4 \text { times }\end{array}$ & $\begin{array}{c}\text { Adrenaline } \\
\mathrm{H} 2 \text {-antihistamines } \\
\text { Oral glucocorticoids }\end{array}$ & \\
\hline & $\begin{array}{l}\text { Pruritus } \\
\text { Flushing } \\
\text { Skin wheals }\end{array}$ & & $\begin{array}{c}\text { H2-antihistamines } \\
\text { Leukotriene antagonist } \\
\text { Disodium cromoglycate NSAID } \\
\text { (if tolerance is known) } \\
\text { Topical glucocorticoids } \\
\text { PUVA } \\
\text { UVA1 } \\
\text { Narrow-band UVB }\end{array}$ & \\
\hline & $\begin{array}{l}\text { Abdominal } \\
\text { pain } \\
\text { Nausea } \\
\text { Diarrhea } \\
\text { Duodenal } \\
\text { ulcers }\end{array}$ & & $\begin{array}{l}\text { H2-antihistamines } \\
\text { Proton pump inhibitors } \\
\text { Oral disodium cromoglycate } \\
\text { Oral glucocorticoids }\end{array}$ & \\
\hline & Anaphylaxis & $\begin{array}{c}\text { Emergency kit: } \\
7.5 \text { to } 25 \text { kg body weight: } 0.15 \mathrm{mg} \\
\text { adrenaline auto-injector } \\
\geq 25 \mathrm{~kg} \text { body weight: } 0.3 \mathrm{mg} \text { adrenaline } \\
\text { autoinjector } \\
\mathrm{H} 1, \mathrm{H} \text {-antihistamines, glucocorticoids }\end{array}$ & $\begin{array}{l}\text { Omalizumab in recurrent anaphylaxis } \\
\text { SIT in Hymenoptera hypersensitivity }\end{array}$ & \\
\hline
\end{tabular}

DCM - diffuse cutaneous mastocytosis, PUVA - UVA plus psoralen, NSAID - non-steroidal anti-inflammatory drugs, MPCM - maculopapular cutaneous mastocytosis, SIT - specific immunotherapy, UP - urticaria pigmentosa, UV - ultraviolet.

tion of burning of the skin may be controlled by first-generation and second-generation $\mathrm{H} 1$ antihistamines [4, 5]. The first-line drugs are non-sedating $\mathrm{H} 1$ antihistamines [4]. However, some patients with refractory symptoms may need increased doses of $\mathrm{H} 1$ antihistamines to control these symptoms. Correspondingly in urticaria, it is recommended to increase the dose up to 4 times the usual daily dose [4, 8]. If symptoms persist although maximum doses of $\mathrm{H} 1$ antihistamines are used, it is reasonable to add $\mathrm{H} 2$ antihistamines and leukotriene antagonist, such as montelukast [4, 5]. The Spanish Mastocytosis Center recommends oral disodium cromoglycate (at a dose of 15-20 mg/kg/day in children, $200 \mathrm{mg}$ every $6 \mathrm{~h}$ in adults) when the patients suffer from gastrointestinal symptoms or developed a reduction in the cholesterol, triglyceride, ferritin, or vitamin $B_{12}$ level [6]. Neverthe- less, oral and topical cromoglycate absorption is minimal and the mechanism of its action remains unclear. In patients with sleep-disturbing symptoms, sedating antihistamines in short-term therapy may be advised [7]. $\mathrm{H} 2$ antihistamines are more effective in gastrointestinal symptoms such as abdominal pain, cramping, diarrhea and gastric hypersecretion [5]. In cases with peptic symptoms, which persist despite $\mathrm{H} 2$ antihistamines therapy, inhibitors of the proton pump are recommended [5]. During the last years, only one controlled clinical trial with $\mathrm{H} 1$ antagonist, rupatadine, was performed in patients with mastocytosis $[4,9]$. The effectiveness of rupatadine in controlling of mediator-related symptoms and improvement of the patient's quality of life has been proved $[4,9]$. Pediatric mastocytosis is mainly limited to the skin disease and transient disease. Therefore, treatment 
should be focused on symptoms control. High-potency topical glucocorticoids (GCS) in short-term therapy or a crystalline steroid solution injection may be administered in symptomatic mastocytoma. Surgical excision of mastocytoma is indicated only when irritation of the lesion causes severe mast cell mediator-related symptoms or anaphylaxis [4, 5]. In general, topical GCs may reduce skin symptoms and lead to cosmetic improvement $[4,5]$. Nevertheless, these medicines should be prescribed only for short-term therapy due to numerous skin side effects including cutaneous atrophy, telangiectasia, hyperpigmentation, hypopigmentation and systemic side effects like osteopenia, or adrenocortical suppression in repeated or extensive application $[4,5,7]$. Systemic GCs are not recommended in CM because of their systemic, serious side effects, particularly diabetes, high blood pressure, osteoporosis, infections, cardiovascular disease and Cushing syndrome. However, systemic GCS can be ordered in short-time therapy in extremely severe CM with mediator-related symptoms or bullous lesions $[10,11]$. Taking into account that pediatric CM is mostly benign disease, only non-sedating $\mathrm{H} 1$ antihistamines are required in the majority of cases.

\section{Second-line therapy}

Phototherapy or photochemotherapy may be considered as therapeutic options because they result in partial remission of skin lesions and pruritus reduction $[4,12,13]$. Recently Brazzelli et al. has published a research report on 20 patients with CM and ISM treated with PUVA-therapy (UVA plus psoralen therapy) and NBUVB (narrow-band UVB) [12]. As the result of the therapy, improvement of skin lesions and reduction of pruritus were achieved [12]. Considering a self-limiting course of childhood-onset mastocytosis, phototherapy is not recommended in children. In general, phototherapy and photochemotherapy in adults are assessed as methods of limited efficacy, because they lead to only partial and temporary improvement of skin signs and symptoms. In addition, the carcinogenic effect of phototherapy and photochemotherapy should be considered, particularly in long-term or recurrent ultraviolet phototherapy which is needed to achieve skin response in CM $[4,12]$. Therefore, it is recommended to use NB-UVA, UVA1 or PUVA therapy as second-line therapy, when antihistamines do not result in reduction of mast cell mediator-related symptoms [4]. Based on the experience of some authors, neodymium-doped yttrium aluminum garnet laser therapy is potentially beneficial for some patients e.g. with a skin lesion on the face. The laser therapy is not widely used in CM due to different intensity and distribution of skin lesions $[4,14]$. Other options, which may be considered in topical treatment of $\mathrm{CM}$, include disodium cromoglycate at a concentration of $0.21-4 \%$ in aqueous solutions and pimecrolimus $[6,15]$.

\section{Potential therapeutic strategies}

In recent years, omalizumab, a monoclonal antibody which selectively binds human IgE, has been shown to be a favorable therapeutic option in mastocytosis associated with recurrent anaphylaxis [4, 16-18]. Kibsgaard et al. reported full remission of anaphylaxis after omalizumab therapy in a 31-year-old male with indolent SM and episodes of idiopathic anaphylaxis [17]. Also Matito et al. reported a case of a 12-year-old girl with CM who was successfully treated with 3 doses of $450 \mathrm{mg}$ with an injection every 4 weeks [18]. These patients had a complete and long-term remission of severe mast cell mediator-related symptoms [18]. So far, despite the beneficial results, the use of omalizumab in patients with mastocytosis associated with recurrent anaphylaxis has been experimental. The results of an ongoing controlled clinical trial have not been published yet.

Imatinib mesylate, an oral tyrosine kinase inhibitor, is approved by the US Food and Drug Administration for treatment of aggressive SM without the D816V KIT mutation or with an unknown mutation status [2]. Therefore, it has a limited role in the treatment of SM patients, the majority of whom harbor D816V KIT mutation. The most common drug side effects were diarrhea and peripheral edema [2]. Interestingly, in recent years, successful administration of imatinib in CM has been reported [1921]. Morren et al. reported 2 children with DCM without D816V KIT mutation treated with imatinib with good response. It is worth mentioning that these 2 patients had a regulatory type of KIT mutation, which are sensitive to imatinib [19]. This therapy resulted in resolution of skin lesions and it was well tolerated [19]. However, the cumulative published findings to date are not sufficient for recommending imatinib in CM therapy.

Masatinib is a new, highly selective oral tyrosine kinase inhibitor that targets wild-type KIT kinase, LYN and FYN kinase which have a crucial role in pathogenesis of mastocytosis [22]. Phase 2 study has shown a beneficial effect in both SM and CM patients, regardless of their KIT mutation status [23]. Randomized, phase 3 study revealed that masatinib is an effective and well-tolerated medicine in severe symptomatic patients with indolent SM [22]. The safety profile of the drug is beneficial, longterm incidence of adverse events was equivalent to placebo [22]. Masatinib may become a promising therapeutic option in CM, however further studies are required.

The cytoreductive therapy in patients with SM usually results in partial or complete remission of cutaneous symptoms [4, 24-28]. Barete et al. reported a positive effect of treatment with cladribine in 3 patients with CM [25]. In the experience of some authors, cladribine is a beneficial treatment with an acceptable safety profile in mastocytosis patients refractory to multiple symptomatic therapies and might be considered as a treatment option in symptomatic CM or indolent SM patients in consid- 
eration of the benefit-risk balance [24-26]. Interferon- $\alpha$ (IFN- $\alpha$ ) is also often considered the first-line cytoreductive therapy in symptomatic SM [2]. It has been reported that remission of skin symptoms was observed as the result of IFN- $\alpha$ therapy in the majority of SM patients [27]. Interestingly, Rosario and Bhat recently reported a successful therapy with IFN- $\alpha$ in a 45 -year-old male patient with CM who received 84 injections of IFN- $\alpha$ (3 million IU twice weekly) [28]. Although the disappearance of skin lesions has been reported as the result of cytoreductive therapies in $\mathrm{SM}$, the use of potentially toxic drugs in $\mathrm{CM}$ is not recommended $[3,4,6,7]$.

The raft modulator such as miltefosine, seems to be a promising option in topical treatment of CM. Based on Hartmann et al. observations, miltefosine decreased wheals and size of skin lesions in patients with CM. Furthermore, the histomorphometric analysis has shown a reduced number of mast cells in the upper papillary dermis [29]. However, in comparison with clobetasol, miltefosine treatment was often associated with eczematous skin irritation [29].

\section{Prevention of the anaphylaxis}

The prevention of the anaphylactic reactions include identification and avoidance of trigger factors for mast cells degranulation. In general, common triggers for mast cells degranulation include Hymenoptera sting, drugs (opioids, non-steroidal anti-inflammatory drugs, muscle relaxants, iodinated contrast media), stress, alcohol, spicy foods, heat, cold and exercise [4, 5, 7, 30, 31]. On the other hand the avoidance of all potential triggers described in the literature is not necessary, but should be individualized according to the patient's experience $[4,7]$. With regard to the high risk of anaphylaxis in adult patients with mastocytosis, being equipped with 2 adrenaline autoinjectors of $0.3 \mathrm{mg}$ is recommended [32]. The risk of anaphylaxis in childhood-onset mastocytosis is lower than in adults. It is estimated to be $5-10 \%$ in children compared with 22-50\% in adults with mastocytosis [7, 31, 33-37]. Hence, there is no consensus whether to prescribe an adrenaline autoinjector for all children with CM [4, 7]. Surely enough, providing an adrenaline autoinjector is recommended for $\mathrm{CM}$ children with an extensive skin involvement, blistering, persistently elevated serum tryptase level and anaphylaxis in medical history $[4,7]$. The adrenaline dose is $0.15 \mathrm{mg}$ for children with 7.5 to $25 \mathrm{~kg}$ body weight and $0.3 \mathrm{mg}$ above $25 \mathrm{~kg}$ body weight [32].

The anesthetic and surgical procedures are the risk factors of mast cell mediator-related symptoms and anaphylaxis in all patients with mastocytosis, however the incidence of perioperative anaphylaxis is low. The surgical procedures and anesthesia should not be avoided in patients with mastocytosis. Nevertheless, mastocytosis patients require prophylactic antimediator therapy (PAT) and adequate anesthetic management. The PAT is based on $\mathrm{H} 1 / \mathrm{H} 2$ antihistamines, glucocorticoids and benzodiazepines given $1 \mathrm{~h}$ before the anesthesia [33, 38]. It is suggested to avoid morphine and codeine [39, 40], thiopental [40], succinylcholine [40], mivacurium [40, 41], atracurium [40, 41], rocuronium [40], nefopam [41]. If opioids are needed, the administration of fentanyl and alfentanil is recommended [41].

Hymenoptera specific immunotherapy (SIT) is recommended in mastocytosis patients with IgE-mediated anaphylactic reactions to honey bee or wasp or both. SIT in Hymenoptera anaphylaxis is the only available option that reduces the risk of life-threatening episodes and should be performed life-long in patients with mastocytosis [42, 43].

To summarize, pure CM in children is mostly a benign and transient disease. Therefore, the main aim of treatment is to control mediator-related symptoms with antihistamines and short-term topical corticosteroids therapy. In adults, the disease limited to the skin is a rarity and treated mainly as a cosmetic problem. In the majority of adults, skin involvement is associated with SM. Thus, drug administration, prevention and follow-up should be individualized depending on disease manifestation.

\section{Conflict of interest}

The authors declare no conflict of interest.

\section{References}

1. Hartmann K, Escribano L, Grattan C, et al. Cutaneous manifestations in patients with mastocytosis: Consensus report of the European Competence Network on Mastocytosis; the American Academy of Allergy, Asthma \& Immunology; and the European Academy of Allergology and Clinical Immunology. J Allergy Clin Immunol 2016; 137: 35-45.

2. Pardanani A. Systemic mastocytosis in adults: 2017 update on diagnosis, risk stratification, and management. Am J Hematol 2016; 91: 1146-59.

3. Valent P, Akin C, Metcalfe DD. Mastocytosis: 2016 updated WHO classification and novel emerging treatment concepts. Blood 2017; 129: 1420-7.

4. Siebenhaar F, Akin C, Bindslev-Jensen C, et al. Treatment strategies in mastocytosis. Immunol Allergy Clin North Am 2014; 34: 433-47.

5. Arock M, Akin C, Hermine O, et al. Current treatment options in patients with mastocytosis: status in 2015 and future perspectives. Eur J Haematol 2015; 94: 474-90.

6. Azańa JM, Torrelo A, Matito A. Update on mastocytosis (part 2): categories, prognosis, and treatment. Actas Dermosifiliogr 2016; 107: 15-22.

7. Broesby-Olsen S, Dybedal I, Gülen T, et al. Multidisciplinary management of mastocytosis: Nordic Expert Group Consensus. Acta Derm Venereol 2016; 96: 602-12.

8. Zuberbier T, Aberer W, Asero R, et al. Methods report on the development of the 2013 revision and update of the EAACI/ GA2 LEN/EDF/WAO guideline for the definition, classification, diagnosis, and management of urticaria. Allergy 2014; 69: e1-29. 
9. Siebenhaar F, Förtsch A, Krause K, et al. Rupatadine improves quality of life in mastocytosis: a randomized, doubleblind, placebo-controlled trial. Allergy 2013; 68: 949-52.

10. Verma KK, Bhat R, Singh MK. Bullous mastocytosis treated with oral betamethasone therapy. Indian J Pediatr 2004; 71: 261-3.

11. Yankova R, Abadjieva T, Belovezhdov V. Cutaneous mastocytosis with persistent blistering: successful treatment with methylprednisolone and 3-year follow-up management. Dermatol Ther (Heidelb) 2015; 5: 145-50.

12. Brazzelli V, Grassi S, Merante S, et al. Narrow-band UVB phototherapy and psoralen-ultraviolet A photochemotherapy in the treatment of cutaneous mastocytosis: a study in 20 patients. Photodermatol Photoimmunol Photomed 2016; 32: 238-46.

13. Guhl S, Hartmann K, Tapkenhinrichs S, et al. Ultraviolet irradiation induces apoptosis in human immature, but not in skin mast cells. J Invest Dermatol 2003; 121: 837-44.

14. Resh B, Jones E, Glaser DA. The cosmetic treatment of urticaria pigmentosa with Nd:YAG laser at 532 nanometers. J Cosmet Dermatol 2005; 4: 78-82.

15. Correia O, Duarte AF, Quirino P, et al. Cutaneous mastocytosis: two pediatric cases treated with topical pimecrolimus. Dermatol Online J 2010; 16: 8.

16. Sokol KC, Ghazi A, Kelly BC, et al. Omalizumab as a desensitizing agent and treatment in mastocytosis: a review of the literature and case report. J Allergy Clin Immunol Pract 2014; 2: 266-70.

17. Kibsgaard L, Skjold T, Deleuran M, et al. Omalizumab induced remission of idiopathic anaphylaxis in a patient suffering from indolent systemic mastocytosis. Acta Derm Venereol 2014; 94: 363-4.

18. Matito A, Blázquez-Gońi C, Morgado JM, et al. Short-term omalizumab treatment in an adolescent with cutaneous mastocytosis. Ann Allergy Asthma Immunol 2013; 111: 425-6.

19. Morren MA, Hoppé A, Renard M, et al. Imatinib mesylate in the treatment of diffuse cutaneous mastocytosis. J Pediatr 2013; 162: 205-7.

20. Vannorsdall EJ, Collins JA, Chen QC, et al. Symptomatic response to imatinib mesylate in cutaneous mastocytosis as sociated with chronic myelomonocytic leukemia. Curr Oncol 2013; 20: 349-53.

21. Hoffmann KM, Moser A, Lohse P, et al. Successful treatment of progressive cutaneous mastocytosis with imatinib in a 2-year-old boy carrying a somatic KIT mutation. Blood 2008; 112: 1655-7.

22. Lortholary O, Chandesris MO, Bulai Livideanu C, et al. Masitinib for treatment of severely symptomatic indolent systemic mastocytosis: a randomised, placebo-controlled, phase 3 study. Lancet 2017; 389: 612-20.

23. Paul C, Sans B, Suarez F, et al. Masitinib for the treatment of systemic and cutaneous mastocytosis with handicap: a phase 2a study. Am J Hematol 2010; 85: 921-5.

24. Lim KH, Pardanani A, Butterfield JH, et al. Cytoreductive therapy in 108 adults with systemic mastocytosis: outcome analysis and response prediction during treatment with interferon-alpha, hydroxyurea, imatinib mesylate or 2-chlorodeoxyadenosine. Am J Hematol 2009; 84: 790-4.

25. Barete S, Lortholary O, Damaj G, et al. Long-term efficacy and safety of cladribine (2-CdA) in adult patients with mastocytosis. Blood 2015; 126: 1009-16.

26. Lock AD, McNamara CJ, Rustin MH. Sustained improvement in urticaria pigmentosa and pruritus in a case of indolent systemic mastocytosis treated with cladribine. Clin Exp Dermatol 2015; 40: 142-5.

27. Casassus P, Caillat-Vigneron N, Martin A, et al. Treatment of adult systemic mastocytosis with interferon-alpha: results of a multicentre phase II trial on 20 patients. Br J Haematol 2002; 119: 1090-7.

28. Rosario A, Bhat RM. Successful treatment of provisional cutaneous mastocytosis with interferon alpha. Indian J Dermatol 2016; 61: 347.

29. Hartmann K, Siebenhaar F, Belloni B, et al. Effects of topical treatment with the raft modulator miltefosine and clobetasol in cutaneous mastocytosis: a randomized, double-blind, placebo-controlled trial. Br J Dermatol 2010; 162: 185-90.

30. Górska A, Niedoszytko M, Lange $M$, et al. Risk factors for anaphylaxis in patients with mastocytosis. Pol Arch Med Wewn 2015; 125: 46-53.

31. Brockow K, Jofer C, Behrendt H, et al. Anaphylaxis in patients with mastocytosis: a study on history, clinical features and risk factors in 120 patients. Allergy 2008; 63: 226-32.

32. Muraro A, Roberts G, Worm M, et al. Anaphylaxis: guidelines from the European Academy of Allergy and Clinical Immunology. Allergy 2014; 69: 1026-45.

33. Matito A, Morgado JM, Sánchez-López P, et al. Management of anesthesia in adult and pediatric mastocytosis: a study of the Spanish Network on Mastocytosis (REMA) based on 726 anesthetic procedures. Int Arch Allergy Immunol 2015; 167: 47-56.

34. Méni C, Bruneau J, Georgin-Lavialle S, et al. Paediatric mastocytosis: a systematic review of 1747 cases. Br J Dermatol 2015; 172: 642-51.

35. González de Olano D, de la Hoz Caballer B, Núńez López R, et al. Prevalence of allergy and anaphylactic symptoms in 210 adult and pediatric patients with mastocytosis in Spain: a study of the Spanish network on mastocytosis (REMA). Clin Exp Allergy 2007; 37: 1547-55.

36. Matito A, Carter M. Cutaneous and systemic mastocytosis in children: a risk factor for anaphylaxis? Curr Allergy Asthma Rep 2015; 15: 22

37. Lange $M$, Niedoszytko $M$, Renke J, et al. Clinical aspects of paediatric mastocytosis: a review of 101 cases. J Eur Acad Dermatol Venereol 2013; 27: 97-102.

38. Czarny JH, Lange M, Niedoszytko MB, et al. Drug hypersensitivity reactions and allergy in patients with mastocytosis. Przegl Dermatol 2017; 104: 22-30.

39. Brockow K, Bonadonna P. Drug allergy in mast cell disease. Curr Opin Allergy Clin Immunol 2012; 12: 354-60.

40. Bonadonna P, Lombardo C. Drug allergy in mastocytosis. Immunol Allergy Clin North Am 2014; 34: 397-405.

41. Dewachter P, Castells MC, Hepner DL, et al. Mouton-Faivre C. Perioperative management of patients with mastocytosis. Anesthesiology 2014; 120: 753-9.

42. Bonadonna P, Zanotti R, Muller U. Mastocytosis and insect venom allergy. Curr Opin Allergy Clin Immunol 2010; 10: $347-$ 53.

43. Niedoszytko M, de Monchy J, van Doormaal JJ, et al. Mastocytosis and insect venom allergy: diagnosis, safety and efficacy of venom immunotherapy. Allergy 2009; 64: 1237-45. 